\title{
Creative Economic Building Components For Low-Income Housing
}

\author{
Basil Kamel, PhD \\ Professor of Architecture and Urban Theory \\ American University in Cairo \\ Cairo, Egypt
}

\author{
Moaz Mohamed \\ Practicing Architect \\ Cairo, Egypt
}

\begin{abstract}
When observing Egypt's method of expansion, one can identify a clear language and distinctive pattern of urban development. The years following 1952, marked by the privatization of agricultural land and the population boom, gave rise to a soon to be urban 'catastrophe'. In order to fulfil the needs of the growing population, buildings were sprouting out everywhere, causing agricultural lands to disappear under a jungle of red bricks, erasing the lines between urban and rural. This phenomenon of informal expansion has spread across the country composing what is commonly known as Ashwa'eeyat or informal settlements. In Egypt, these can be identified by a unified method of construction using concrete skeleton structures of concrete slabs and beams along with plain red brick walls; an appearance that does not reflect nor shed light on the Egyptian culture or environmental requirements. The use of bricks and concrete is due to the fact that this construction method is the most commonly used and feasible type of construction; the material is available, the workmanship, even though it is not the most economic method. Egypt is a developing country that possesses numerous resources, being both tangible and intangible ones. The aim of this paper is to research and determine the possibility of creating different elements of construction utilizing available resources and recycling waste material. These elements would be economic and reflective of the Egyptian culture while maintaining the necessary environmental and physical safety requirements sought in residential buildings.
\end{abstract}

Keywords: recycled materials; alternative wall; construction waste; informal; economic construction alternative

\section{INTRODUCTION}

Analyzing the informal urban fabric at the fringes of the city of Cairo, a significant sense of physical uniformity is apparent due to the use of specific materials and construction systems. The use of exposed red bricks with skeleton type concrete structures is the norm of construction although these materials and construction methods are non-economic and do not satisfy environmental requirements (Figure $1 \&$ Figure 2). There are very little studies that address potential of recycling waste material for environmental solutions and as means to enhance economic vitality for community development on the one hand, and better define local identity on the other (MOPIC, 2004).

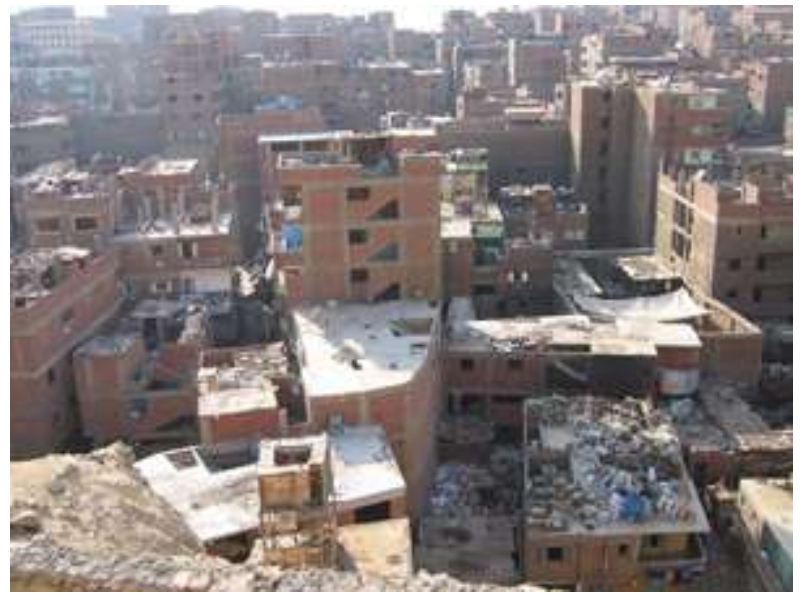

Figure 1. Informal Settlements of Izbet Khayralla.

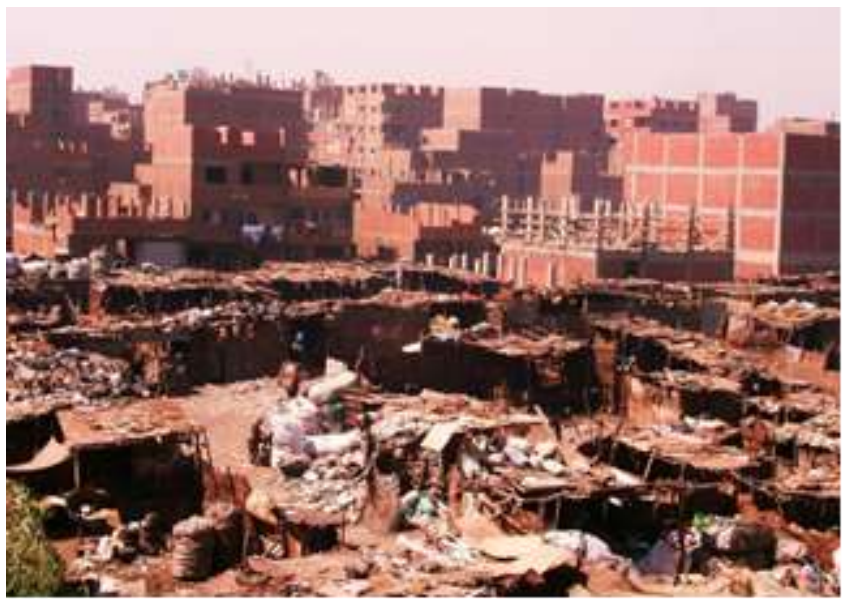

Figure 2. Informal Settlements of Dar El Salam.

Figure 3 illustrates that Cairo is considered one of the major concentrations for slums and dilapidated communities (AbuLughod \& Sims, 2010). Approaches for development and providing for housing should involve creative models that address the resources and potentials of these communities (Revedin, 2012). By identifying these potentials; be they tangible (natural, physical resources such as materials, site conditions, etc..) or intangible ones (craftsmanship, etc.) one can achieve creative models of development. This paper aims to develop creative new wall construction through the use of available resources and recycled waste materials both from the potentials of a local community (taken as a case study) and the nation resources. This model, as developed, shall serve as an exemplary process aimed to be repeated around the country. It shall re-enforce connection at a socio-cultural 
level through the use of existing resources on the ground of mutual benefit and collaborative work.

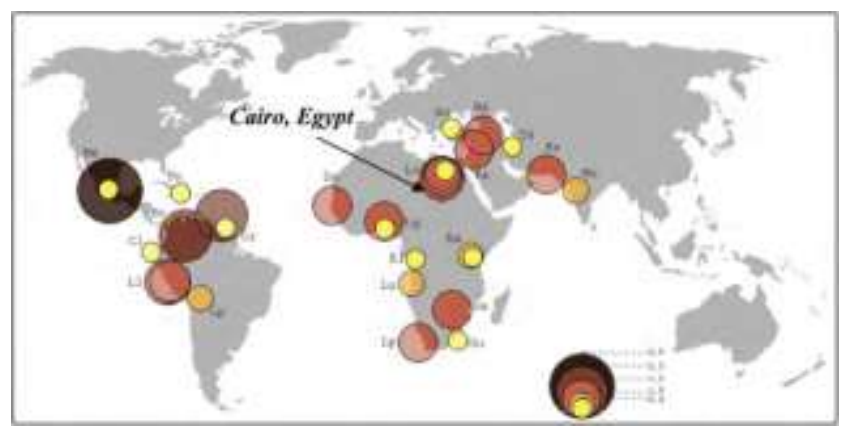

Figure 3. Figure illustrating the 30 mega slums of the world with Cairo amongst the top ranked.

A community site at Khaya $\neg$ la lying in Fustat area was chosen as the case study. The variable sub-communities within this site posses resources (represented in man power/people, waste bi products and craftsmanship) that gear towards developing a potential economic creative model for building materials concentrating on new wall systems. It also aims to involve the local community through empowerment and raising awareness of potentials for socio-economic development (GIZ \& KFW, 2012).

The Khayala site's activity patterns generate a significant amount of wasted bi products that could be otherwise the key develop alternative construction material (Figure 4). On one hand, AlKhayala site is a zone containing stone workshops that work with Sandstone, Basalt and granite, which are handcrafted to produce various types of wall claddings, flooring and ornamentation. The workers sell the stone they hand carve and craft while disposing all the waste stone out of the site after paying a fee for each loading. On the other hand, there exists a large supply of materials within the nation that are not used to their fullest potential such as palm fronds and rice husk (Jahromi et al, 2007). In fact, a large amount of rice husk is burnt every year by peasants and farmers because they consider it useless (Razavi, 2005).

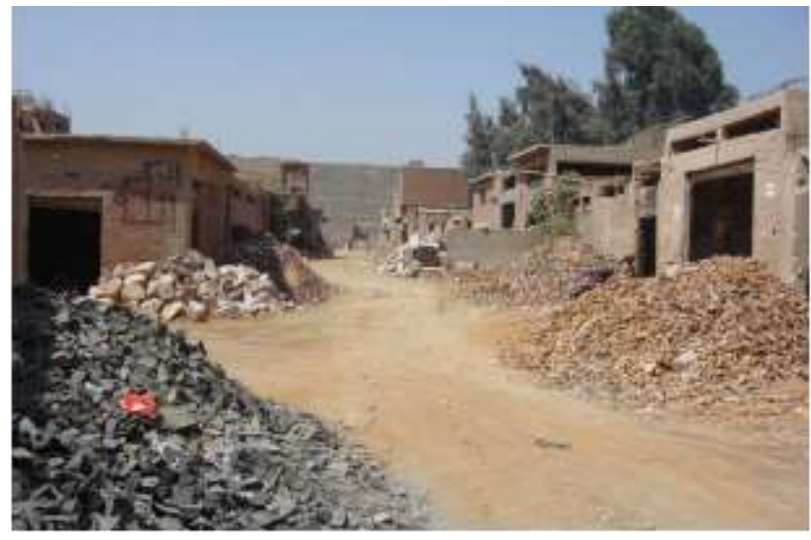

Figure 4. Waste basalt, sandstone and granite located on site

The basic hypothesis of this research assumes that by conducting research about the different available practices of material use and the potentials born from recycled waste materials both at the level of the community and nationwide, the design and creation of alternate wall components could be proposed. This shall substitute the existing dominant language (or system) of facades in most informal neighborhoods of Cairo and Egypt, and thus creating a new system that could be a seed for a new socio-cultural local identity. The component is considered one of the approaches of development within a wider scope project, attempting to alter the present schemes, while reviving and redefining tomorrow's heritage.

\section{METHODOLOGY}

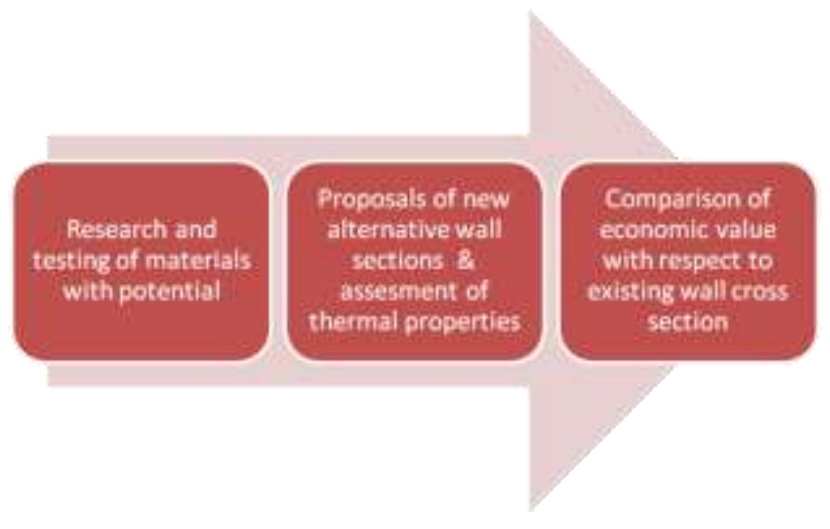

Figure 5. Diagram of methodology (researchers)

The research relied on both a literature review and empirical studies to identify the potentials and material resources and types available in the community. A process of material identification was conducted in order to highlight the strengths, features, characteristics and weaknesses of each material; information such as availability, material strength, source and potentials. This process of identification relied on ASTM standard test methods results.

Based on this information, new alternatives and wall components with the use of waste material identified from different locations and sources were proposed. The proposal phase included the assessment of the wall sections' thermal properties to ensure their physical and environmental qualities. The final phase involved an economic analysis comparing the wall sections with respect to the dominant brick wall commonly used in Egypt. This was conducted to assess the feasibility, economic significance and tendency of the wall components to contend within the local market, especially in informal areas.

\section{MATERIAL IDENTIFICATION}

\subsection{Briefing}

In this sector, the process of identifying the material will take place, revealing the following components:

$\begin{array}{ll}\text { - } & \text { Sources of material } \\ \text { - } & \text { Quantity of material } \\ \text { - } & \text { Potentials of material } \\ \text { - } & \text { Properties and features (through research and testing }\end{array}$ (ASTM))

- Treatments (if required).

\subsection{Characteristics and Features}

\subsubsection{Stone}

Each workshop on the premises of the site produces a daily average of $350 \mathrm{~kg}$ of waste stone. There are 120 different workshops within the site. There are 55 workshops working with basalt, 40 workshops working with Sandstone and 25 
workshops working with granite. The site produces an average of $1,260,000 \mathrm{~kg}$ (1,340 tons) of waste stone monthly. The stone located on the site is of various types, including Basalt, granite and sandstone (locally known as 'Hashmi').

\subsubsection{Basalt}

Basalt is a dark-colored, fine-grained, igneous rock composed mainly of plagioclase and pyroxene minerals (Subramanian, 2010). Basalt is used as a finishing material embedded on building facades and as finishing material for road networks in high-end residential compounds and districts.

Properties - Testing results:

ASTM C 97-02, standard test method for, "Absorption and Bulk, Specific Gravity of Dimension stone"

ASTM C 170-99, standard test method for "Test for Compressive strength of Dimension stone", Dry conditions

ASTM C 99-2000, Standard test method for "Test for Modulus of Rupture of Dimension stone ", Wet Conditions

Table 1. Standard Specification for Basalt Dimension Stone

\begin{tabular}{|c|l|l|c|}
\hline $\begin{array}{l}\text { Compressive } \\
\text { strength } \\
\left(\mathbf{n} / \mathbf{m m}^{2}\right)\end{array}$ & $\begin{array}{l}\text { Bulk } \\
\text { specific } \\
\text { Gravity }\end{array}$ & $\begin{array}{l}\text { Water } \\
\text { absorption } \\
(\%)\end{array}$ & $\begin{array}{l}\text { Modulus } \\
\text { of } \\
\text { Rupture } \\
\left(\mathbf{n} / \mathbf{m m}^{2}\right)\end{array}$ \\
\hline 108.2 & 2.7 & 0.71 & 20.26 \\
\hline
\end{tabular}

\subsubsection{Granite}

Granite is a light-colored igneous rock with grains large enough to be visible with the unaided eye. Granite is mainly composed of quartz and feldspar. This mineral composition usually gives granite a red, pink, gray or white color with dark mineral grains visible throughout the rock (Robertson, 1988).

Properties - Testing results:

ASTM C615 / C615M

Table 2. Standard Specification for Granite Dimension Stone

\begin{tabular}{|c|c|c|c|}
\hline $\begin{array}{l}\text { Compressive } \\
\text { strength } \\
\text { (n/mm }\end{array}$ & $\begin{array}{l}\text { Bulk } \\
\text { specific } \\
\text { Gravity }\end{array}$ & $\begin{array}{l}\text { Water } \\
\text { absorption } \\
\text { (\%) }\end{array}$ & $\begin{array}{l}\text { Modulus } \\
\text { of } \\
\text { Rupture } \\
\left(\mathbf{n} / \mathbf{m m}^{2} \text { ) }\right.\end{array}$ \\
\hline 131 & 25 & 0.40 & 10.32 \\
\hline
\end{tabular}

\subsubsection{Sandstone}

Sandstone is a sedimentary rock composed of sand-sized grains of mineral, rock or organic material. It also contains a cementing material that binds the sand grains together and may contain silt sized particles that occupy the spaces between the sand grains. Sandstone is often mined for use as a construction material or as a raw material used in manufacturing (Torabi, 2013).

\section{Properties - Testing results:}

ASTM C616 / C616M

Table 3. Standard Specification for Sandstone Dimension Stone

\begin{tabular}{|l|l|l|l|}
\hline $\begin{array}{l}\text { Compressive } \\
\text { strength }\end{array}$ & $\begin{array}{l}\text { Bulk } \\
\text { specific }\end{array}$ & $\begin{array}{l}\text { Water } \\
\text { absorption }\end{array}$ & $\begin{array}{l}\text { Modulus } \\
\text { of }\end{array}$ \\
\hline
\end{tabular}

\begin{tabular}{|c|c|l|c|}
\hline$\left(\mathbf{n} / \mathbf{m m}^{\mathbf{2}}\right)$ & Gravity & $\mathbf{( \% )}$ & $\begin{array}{c}\text { Rupture } \\
\left(\mathbf{n} / \mathbf{m m}^{2}\right)\end{array}$ \\
\hline 34 & 3 & 4 & 2.91 \\
\hline
\end{tabular}

\subsubsection{Rice Husk}

An available resource widely spread within Egypt specifically within Upper Egypt. Every year, the peasants tend to burn the rice husk into ashes, creating a much-polluted environment. The rice husk is known for its high thermal performance and insulation (Ramezanianpour, 1997). It needs to be cured and compressed in order to form usable sheets to be implemented for different uses (Ramezanianpour, 2009).

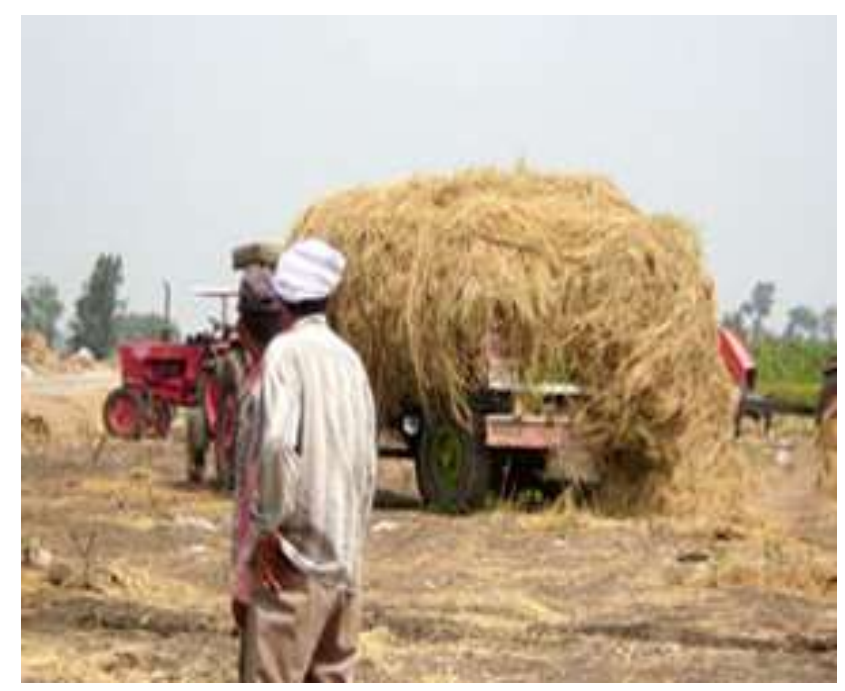

Figure 5. Rice husk is extensively present in Lower Egypt agricultura areas

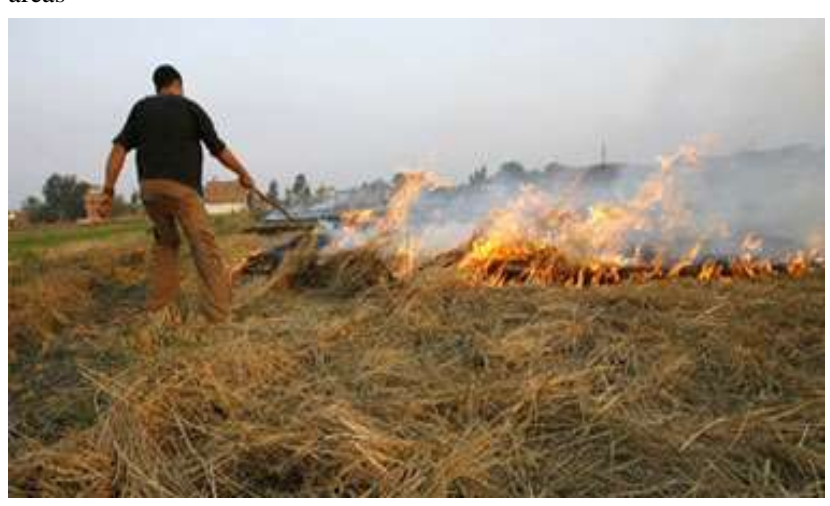

Figure 6 . Rice husk unused and burnt by peasants and farmers

\subsubsection{Palm Fronds}

Egypt is ranked the second worldwide country possessing date palm trees. Around 7,000,000 palm trees are located within the country carrying a large amount of palm fronds. The fronds have been used for years in Upper Egypt for various components and tools. Palm fronds are characterized to be extremely strong, fiber based and durable. It is a widely available and renewable material that has great potentials. This material has been used to produce furniture and containers due to its physical traits but was never pushed further until lately (Suryawanshi, 2013). 


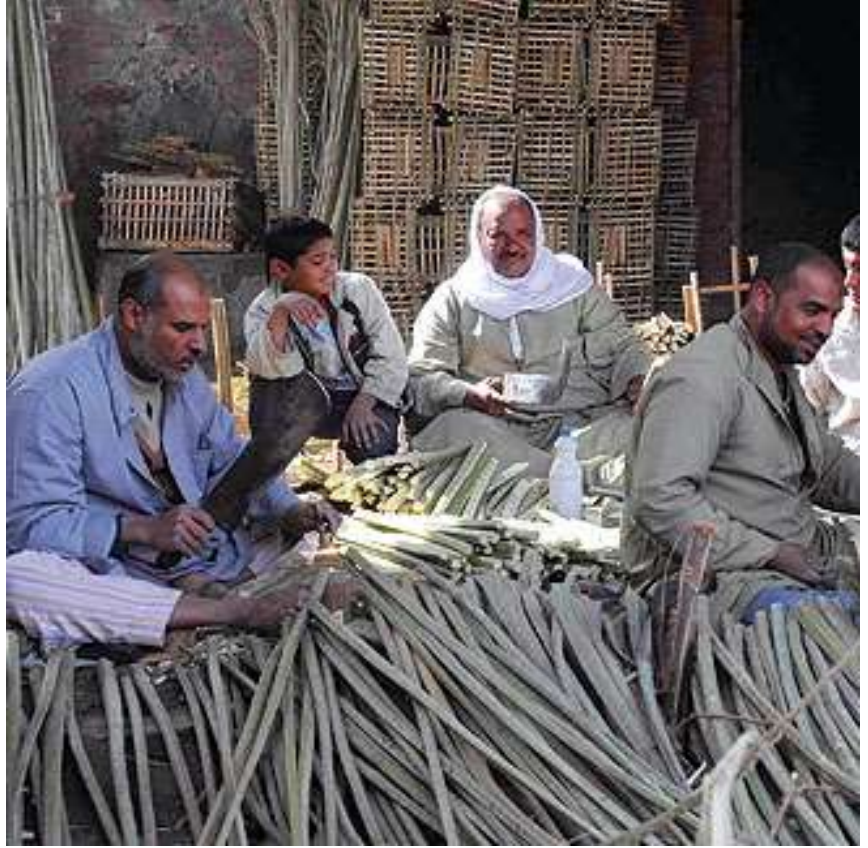

Figure 7. Palm fronds being fabricated to small containers in Upper Egypt

\subsection{Analytical Review}

After the process of material identification, it could be concluded that the nation possesses a large quantity and supply of material that is considered waste, however it is not used efficiently. In order to put these materials to good use, a process of empowering and tutoring of people is required, in order for them to understand the 'know how' of using the material and the connections or sources required in order to attain the material (GIZ 2, 2012). The rice husk, stones of different types and the fronds are concluded to have strong insulating properties (Bowman et al, 1992, \& Marthong, 2012 $\&$ Robertson, 1988). They could be used as filling material or layers in the process of wall creation to attain good thermal conductivity features.

The Basalt and granite have proven to have high compressive strength, feasibly qualifying them to be used as structural components (Hamadallah, 2008 \& Sosna, 2013). The palm fronds is a material of very interesting features that could be used in a variety of methods; it has proven to have high compressive strength and a relatively low weight in addition to it being a fiber based component that could be easily manipulated and shaped (Shamsi, 2009).

After understanding the materials and their properties, we work to identify the possible configurations that would assemble wall sections of adequate properties and features.

Proposal 1 is a wall that is composed of palm fronds, rice husk and stone that attempts to produce a lightweight wall that could be used to envelope auxiliary functions and temporary structures.

Proposal 2 is a building block that is composed of stone, rice husk and cement in an attempt to replace the red brick with a building block of higher performance (Mehta, 2004), and has an aesthetical and cultural value represented in the use of stone and the appearance of the block configuration.

Proposal 3 is a decorative component referred to as stone paste and is used to form various shapes due to its fluidity prior to hardening, and is composed of cement, gypsum and waste crushed stone.

\subsection{Wall Sections Proposed}

\subsubsection{Proposal 1-Palm fronds, rice husk and stone}

The first proposed wall section uses a combination of the waste stone material located on site along with the use of palm fronds from Upper and Lower Egypt, PVC waste pipes from industrial facilities in $6^{\text {th }}$ October city and rice husk from Lower Egypt. The idea is to use the palm fronds and stone as a replacement to reinforced steel bars implemented in structural concrete columns since the basalt stone and granite have a high compressive strength and the palm fronds attain $85 \%$ the strength of reinforced steel, making huge savings on cost which will be analyzed later on in the paper. The idea is to create and pour a strong base to the structural column using concrete filled with waste stone aggregates of large sizes while a PVC pipe is imbedded in its core, rising up as a core for the column. The column would then have stone of smaller sizes placed into it with the addition of cement mortar to create a strong column structure. After that the palm fronds will be fabricated and manipulated to create wall outer shells with no filling on the inside. The columns should be maximum $2 \mathrm{~m}$ apart from each other for issues regarding bracing and lateral stability. The shells will be totally solid and will act as a container. The waste stone material on the other hand after being broken to smaller sizes will be used as the insulating filling material between the interior and exterior palm fronds wall shells.
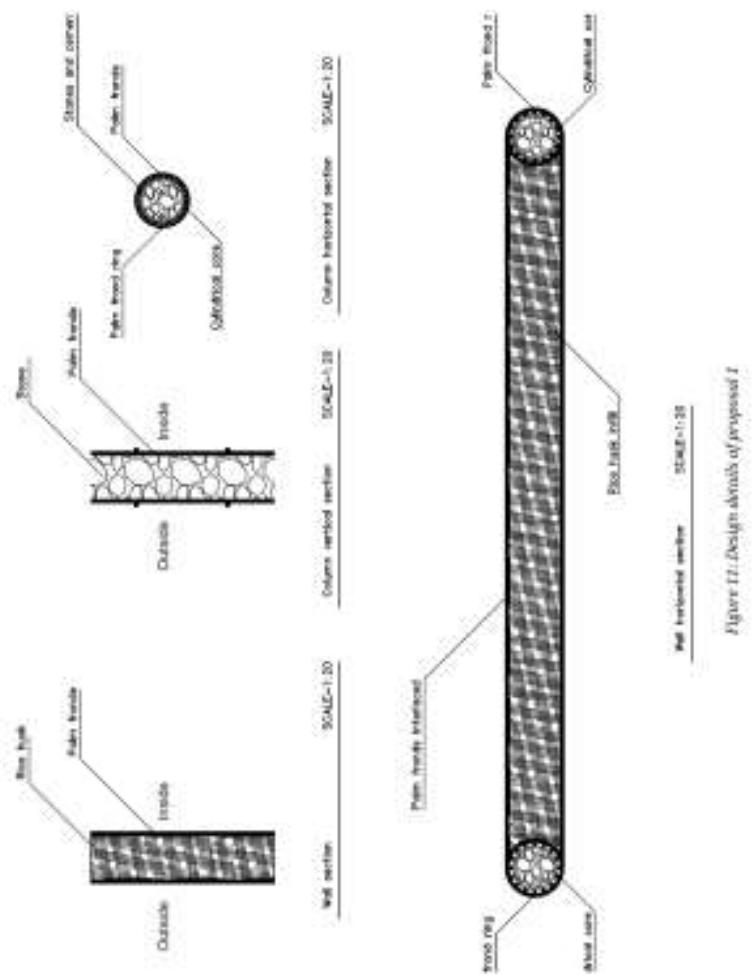

Figure 8. Design details of proposal 1 


\subsubsection{Implementation and Construction Methods}

Steps of implementation

Column construction

1. Cut the palm fronds and categorize the different cross sections

2. Add strands of palm fronds and tie to the extruding palm fronds from the column foundation (Ashayer)

3. Use a waste PVC pipe of $10 \mathrm{~cm}$ radius or so to act as the core of the column

4. Pour concrete into the PVC core with palm fronds (Ones that have tied with the foundation)

5. Use the thick (highest strength) portion of the palm fronds to encircle the core and tie a strand of the lighter fronds to hold them all together.

Wall construction

1. Prepare and work on the intertwining of palm fronds together to create large span palm fronds

2. Use the large span strands to wrap the fronds around the columns

3. Apply several layers ensuring there are no hollow openings between the strands

4. Pour the stone into the shell of palm fronds between two columns.

\subsubsection{Thermal Conductivity}

\begin{tabular}{|l|l|}
\hline U.Value (W/m2.K): & 0.120 \\
\hline Admittance $(\mathrm{W} / \mathrm{m} 2 . \mathrm{K}$ ): & 1.190 \\
\hline Solar Absorption (0-1): & 0.531 \\
\hline Visible Transmittance [0-1]): & 0 \\
\hline Thermal Decrement (0-1): & 0.07 \\
\hline Thermal Lag (hrs): & 5 \\
\hline [SBEM] CM 1: & 0 \\
\hline [SBEM] CM 2: & 0 \\
\hline Thickness (mm): & 450.0 \\
\hline Weight (kg): & 92.000 \\
\hline
\end{tabular}

Figure 9. Ecotect results for Proposal 1 wall section

The proposed wall section has been built and formulated on Autodesk Ecotect, an analysis sustainable building design software that offers building energy analysis tools for architects. The material was tested to attain the thermal conductivity and properties of the proposed wall section being:

U-value: Measure of heat loss

- $\quad$ Admittance: Material's ability to absorb and release heat from a space

- Solar absorption: Amount of solar energy absorbed by wall that is neither reflected nor transmitted

- Thermal lag: Materials required time to add or remove heat from a mass before it reaches the design set point temperature
Analyzing proposal 1, it could be established that the wall section has a relatively low $\mathrm{U}$-value and admittance of 0.12 due to the very high use of rice husk as a filling material of the wall's core; it has relatively high insulating properties (Zhang \& Malhotra, 1996). The wall was also able to achieve a neutral solar absorption ratio of 0.531 and a thermal lag of 5 hours. The wall could be characterized to be light weighted and a very suitable wall component for the construction of light structures. This is due to the limitations of both the palm fronds and the rice husk that are expected to decay within a certain time frame and will need replacement.

\subsubsection{Proposal 2-Stone Block}

The second proposed wall section intends to introduce a building block composed of stone waste, rice husk and cement. The idea is to design a building block to replace the red bricks being used today by a stronger and a more environmental building block. The block will be designed to contain waste stone blocks ranging from $8-12 \mathrm{~cm}$ diameter along with rice husk and cement mortar with hollow openings in its core to lighten its weight. This proposal requires both the design of the mold and the mix.

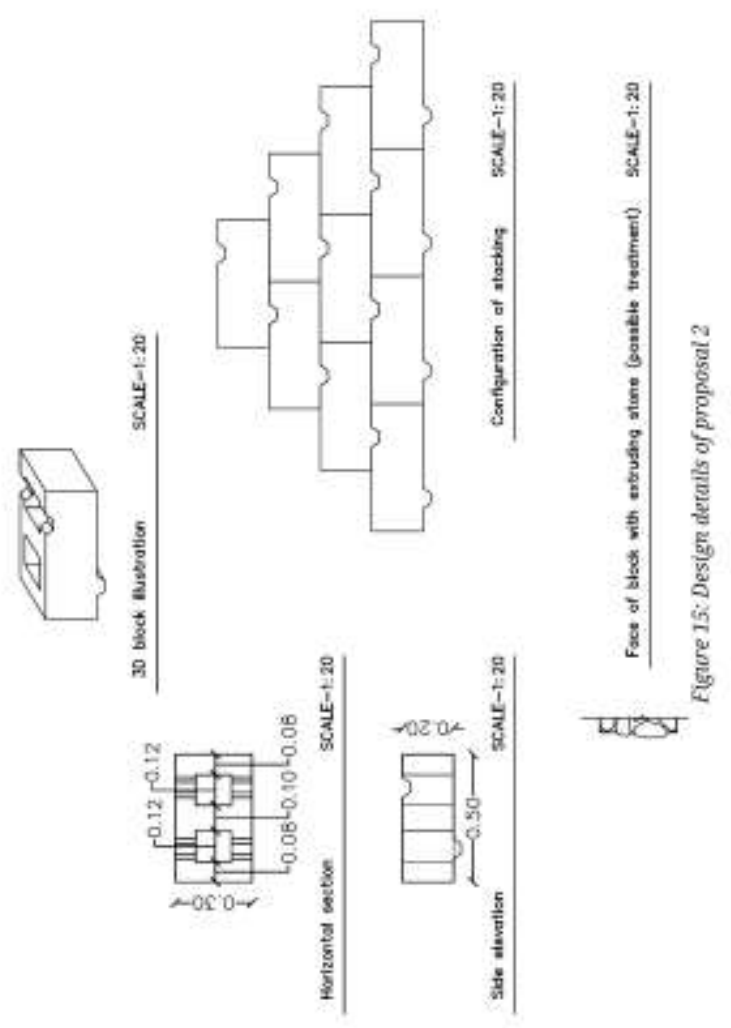

Figure 10. Design details of proposal 2 


\subsubsection{Implementation and Construction Methods}

Steps of implementation

1. Design and fabricate a mold with openings

2. Sieve the stone to achieve required stone size

3. Place the waste stone in the mold

4. Prepare the mixture of rice husk, cement, sand and water

5. Pour the mixture into the mold over the placed waste stone

6. Leave the mixture in the mold to harden

7. Use the building block in the same method use the thick (highest strength) portion of the palm fronds to encircle the core and tie a strand of the lighter fronds to hold them all together.

3.4.2.2 Thermal Conductivity

\begin{tabular}{|l|l|}
\hline U-Value [W/m2.K]: & 0.730 \\
\hline Admittance (W/m2.K]: & 0.990 \\
\hline Solar Absorption [0-1]: & 0.531 \\
\hline Visible Transmittance [0-1]: & 0 \\
\hline Thermal Decrement [0-1]: & 0.03 \\
\hline Thermal Lag (hrs]: & 5 \\
\hline [SBEM] CM 1: & 0 \\
\hline [SBEM] CM 2: & 0 \\
\hline Thickness (mm]: & 320.0 \\
\hline Weight (kg): & 439.917 \\
\hline
\end{tabular}

Figure 10. Ecotect results for Proposal 2 wall section

The proposed wall section has been built and formulated on Autodesk Ecotect that is an analysis sustainable building design software that offers building energy analysis tools for architects. The material was tested to attain the thermal conductivity and properties of the proposed wall section being:

- U-value: Measure of heat loss

- Admittance: Material's ability to absorb and release heat from a space

- Solar absorption: Amount of solar energy absorbed by the wall that is neither reflected nor transmitted

- Thermal lag: Material's required time to add or remove heat from a mass before it reaches the design set point temperature

Analyzing proposal 2, it could be established that the wall component possesses a low U-Value and admittance values due to the stone's (collectively) high insulating properties. The wall section was able to achieve reasonable solar admittance values along with a 5 hour thermal lag achievement. The wall component is considered relatively heavy in comparison with existing building blocks such as red bricks but however has much higher environmental performance and an aesthetical component with the extruding stone element.

\subsubsection{Proposal 3-Stone paste| Decorative}

The third proposed wall section uses a combination of waste stone material located on site, gypsum, and white cement. The gypsum and cement are located in Ain El Sira zone within a 2 $\mathrm{km}$ radius from the site where workshops and markets of cornices and decorative elements exist (GIZ, 2012). The idea is to crush the stone into very small fragments within the $1 \mathrm{~cm}$ range. After that, a combination of the gypsum and white cement is added to the stone fragments to create a paste like component. On the other hand, there is an approach of creating molds of various forms into which the paste can be poured into. The shapes do not have to be linear or regular and could provide limitless designs, patterns and shapes. The shapes could also include the embedding of external components such as flower boxes within the wall. The molds could contain extruding members that would be used to interlock and attach to neighboring blocks like Lego parts (tongue and groove connections). Palm fronds could be implemented within the walls to add to its strength depending on the use and nature of the wall design.

\subsubsection{Implementation and Construction Methods}

Steps of implementation

1. Crush small size stone using stone crushing machine

2. Sieve stone particles to achieve maximum size of $1 \mathrm{~cm}$ radius

3. Create mold with intended design either engraved or intrusions or extrusions, etc.....

4. Prepare the mixture of white cement and gypsum

5. Mix the stone particles with the mixture prepared to create paste

6. Pour the paste into the mold

7. Leave paste to harden

8. Move block to specified location (Cast in place if selected block is one with connection with floor slab)

9. Move block to attach to other blocks through tongue and groove connections created in the poured block.

10. Apply desired finishes to interior and exterior (if preferred)

\subsubsection{Thermal Conductivity}




\begin{tabular}{|l|l|}
\hline U-Value [W/m2.K]: & 4.340 \\
\hline Admittance [W/m2.K]: & 4.600 \\
\hline Solar Absorption [0-1]: & 0.531 \\
\hline Visible Transmittance [0-1]: & 0 \\
\hline Thermal Decrement [0-1]: & 0.96 \\
\hline Thermal Lag (hrs]: & 5 \\
\hline [SBEM] CM 1: & 0 \\
\hline [SBEM] CM 2: & 0 \\
\hline Thickness (mm): & 100.0 \\
\hline Weight (kg): & 248.850 \\
\hline
\end{tabular}

Figure 11. Ecotect results for Proposal 3 wall section

The proposed wall section has been built and formulated on Autodesk Ecotect that is an analysis sustainable building design software that offers building energy analysis tools for architects. The material was tested to attain the thermal conductivity and properties of the proposed wall section being:

- U-value: Measure of heat loss

- Admittance: Material's ability to absorb and release heat from a space

- Solar absorption: Amount of solar energy absorbed by the wall that is neither reflected nor transmitted

- Thermal lag: Material's required time to add or remove heat from a mass before it reaches the design set point temperature

Analyzing proposal 3, it could be concluded that the wall section has achieved average U-Value of 4.340, Admittance of 4.6,solar absorption of 0.531 and a thermal lag of 5 hours. The results are relatively low due to the fact that this building element possesses a small cross section. The component is intended to be used as a decorative element.

\section{Analytical and Comparative Review}

In order to be able to assess the thermal properties of the proposed wall sections, a comparative review should be constructed to compare the proposed with the existing wall sections commonly used and sought to be replaced..

\begin{tabular}{|l|l|}
\hline U-Value (W/m2.K]: & 1.950 \\
\hline Admittance [W/m2.K]: & 4.550 \\
\hline Solar Absorption [0-1]: & 0.495 \\
\hline Visible Transmittance (0-1): & 0 \\
\hline Thermal Decrement (0-1]) & 0.39 \\
\hline Thermal Lag (hrs]: & 7.8 \\
\hline [SBEM] CM 1: & 0 \\
\hline [SBEM] CM 2: & 0 \\
\hline Thickness (mm): & 230.0 \\
\hline Weight (kg]: & 452.500 \\
\hline
\end{tabular}

Figure 12. Ecotect results for double brick wall

\begin{tabular}{|l|l|}
\hline U-Value (W/m2.K]: & 2.620 \\
\hline Admittance (W/m2.K]: & 4.380 \\
\hline Solar Absorption [0-1]: & 0.418 \\
\hline Visible Transmittance (0-1): & 0 \\
\hline Thermal Decrement (0-1]: & 0.7 \\
\hline Thermal Lag (hrs): & 3 \\
\hline [SBEM] CM 1: & 0 \\
\hline [SBEM] CM 2: & 0 \\
\hline Thickness (mm): & 130.0 \\
\hline Weight (kg): & 245.000 \\
\hline
\end{tabular}

Figure 13. Ecotect results for double brick wall.

\section{Economic Analysis \& Conclusion}

In order to achieve a successful component that would actually be able to attain success and replace the existing building block of red bricks, the economic value of the product and component should be intriguing and competitive. The economic aspect is the main factor that people seek since their aim is to reduce the building expenses as much as possible.

Below is a table including the prices of the various construction materials to be used in the analysis and comparison of the proposed components:

\begin{tabular}{|c|c|}
\hline Material & Price \\
\hline Sand & 30 LE per $\mathrm{m}^{3}$ \\
\hline Cement & 500-600 LE per $50 \mathrm{~kg}$ \\
\hline Stones & 0 \\
\hline Rice husk & (transportation fee) \\
\hline Steel & 5100-5700 LE per ton \\
\hline Aggregates & 100 per $\mathrm{m}^{3}$ \\
\hline Red Bricks & 300 per 1000 bricks \\
\hline Palm fronds & 100 LE per ton \\
\hline Gypsum & $375 \mathrm{LE}$ \\
\hline
\end{tabular}

Figure 13. Table illustrating the market value of the different building components and materials

\subsubsection{Methodology of Comparison}

In order to correctly measure the true value of each wall component, it was only relevant to calculate the value of construction of a whole wall. The comparison process will take place between the proposed wall section of the building block and the existing commonly used wall cross section of single layered and double layered red brick since they will be within the same category. The wall that will be built and economically weighed is a $3 \mathrm{X} 4 \mathrm{~m}$ wall. Furthermore, analysis and cost of the two other remaining proposed components will be presented to test their feasibility and tendency to contribute as a contender in the present market.

\subsubsection{Existing Brick wall}

Questioning market and method of payment:

Observing and surveying engineers and personnel involved in the Egyptian market and construction industry, it was analyzed and concluded that the price of purchasing 1000 bricks would range from $300 \mathrm{LE}$ to $350 \mathrm{LE}$.

Price of bonding material: 
Price of cement mortar required to bond 1000 bricks can account for an extra 75 LE.

Number of blocks required:

$3 \mathrm{~m} / 0.07 \mathrm{~m}$ (accounting for cement mortar $1 \mathrm{~cm})=42.86=43$ rows of brick

$4 \mathrm{~m} / 0.13 \mathrm{~m}$ (accounting for cement mortar $1 \mathrm{~cm}$ ) $=30.76=31$ bricks per row

$43 \times 31=1333$ bricks are required to build the wall of area $(4 \mathrm{X} 3 \mathrm{~m})$

Price of wall:

Single wall:

$(1333 / 1000) \times 425$ (price of bricks and mortar)=566.52 LE

Double wall:

(2666 / 1000) X 425 (price of bricks and mortar)= 1133 LE

\subsubsection{Palm fronds, rice husk and stone}

The required quantity of material to compose this proposed wall will acquire the following:

- $\quad$ Around 300 palm fronds will be needed to be components of wall shell and column reinforcement, weighing around $750 \mathrm{~km}$

- Volume of $3 \mathrm{~m}^{3}$ of rice husk

- Volume of $0.36 \mathrm{~m}^{3}$ of stone

- $\quad 3$ PVC waste pipes

Prices:

- $\quad$ Palm fronds $=30 \mathrm{LE}$

- $\quad$ Rice husk $=0$ LE (transportation and compression fee of 100-150 LE)

- $\quad$ Stone $=0 \mathrm{LE}(72 \mathrm{LE}$ price of crafted stone they sell)

- $\quad$ Waste PVC pipes $=20 \mathrm{LE}$

The total value required to construct the proposed wall section is 200-250 LE of material, excluding the cost of labor and neglecting the price of stone.

\section{Proposal 2 - Stone block}

Given that the wall requires $12 \mathrm{~m}^{2}$ coverage, the calculation of the number of blocks required takes place. The coverage (elevation) of the stone block is $(20 \times 30 \mathrm{~cm})$ :

\section{Price of single building block:}

- Alternative 1 (Assuming that the waste left over the stone is sold with the same price of the stone crafted) :

The first step is to calculate the volume of the block: $\left(\right.$ Block $\left.=0.5 \mathrm{~m} \mathrm{X} 0.2 \mathrm{~m} \mathrm{X} 0.3 \mathrm{~m}=0.3 \mathrm{~m}^{3}\right)-($ Voids $=2(0.12 \mathrm{~m} \mathrm{X}$ $0.12 \mathrm{~m}$ Xo. $\left..2 \mathrm{~m})=0.0028 \mathrm{~m}^{3}\right)=0.0272 \mathrm{~m}^{3}$

The volume of a single block that accounts for $\mathbf{0 . 0 2 7 2} \mathbf{m}^{3}$ is then subdivided to contain $70 \%$ stone and $30 \%$ cement mortar. This means that $0.019 \mathrm{~m}^{3}$ of the volume will be composed of stone and $0.00816 \mathrm{~m}^{3}$ of the volume composed of cement mortar components of sand, cement and water.
By multiplying the volume of stone by the price of stone (200 LE for $\mathrm{m}^{3}$ ), it could be concluded that the price of the stone component in a single building block is $3.80 \mathrm{LE}$.

By dividing the ratio of cement mortar into its three components and multiplying them by their respective market values we could conclude that the prices of these elements for a single building block are as follows:

Cement: $3.06 \mathrm{LE}$

Sand: $0.17 \mathrm{LE}$

Water: (Assumed exaggerated value of $0.05 \mathrm{LE}$ )

It could then be summed up that the value of composing a single building block is $7.08 \mathrm{LE}$.

- Alternative 2 (Assuming that the waste left over stone is of no value since it is thrown away):

It could then be summed up that the value of composing a single building block is $3.82 \mathrm{LE}$.

Price of bonding material:

No bonding material is required for the assembly; the wall is connected by a tongue and groove embedded in the building blocks.

Number of blocks required:

$3 \mathrm{~m} / 0.2 \mathrm{~m}$ (length of block) $=15$ rows of blocks

$4 \mathrm{~m} / 0.5 \mathrm{~m}$ (width of block) $=8$ bricks per row

$15 \times 8=120$ stone blocks are required to build the wall of area $(4 \times 3 \mathrm{~m})$

Price of wall:

Alternative 1:

7.08 LE X $120=849.60$ LE

Alternative 2:

3.80 LE X $120=456$ LE

Logically speaking, Alternative 2 of calculation would be the price of the product with no profit value.

\section{Proposal 3 - Stone paste | Decorative}

The required quantity of material to compose $1 \mathrm{~m}^{3}$ of this proposed wall will acquire the following:

- Stone: $0.45 \mathrm{~m}^{3}$

- White cement mortar: $0.15 \mathrm{~m}^{3}$

- Gypsum: $0.20 \mathrm{~m}^{3}$

- Rice husk: $0.20 \mathrm{~m}^{3}$

Prices:

- Stone: 0 LE (90 LE price of crafted stone they sell)

- White cement mortar: 120 LE

- Gypsum: 75 LE

- Rice husk: 0 LE (transportation and compression fee of 10-15 LE)

The total value required to construct the proposed wall section is $90 \mathrm{LE}$ of material, excluding the cost of labor and neglecting price of the stone and the mold fabrication. 


\section{Conclusion}

The assessment of the proposed wall sections on both the physical and economic levels, reveals that the proposed wall cross sections represent a good approach to treating the projected problem as stated; overcoming the vanishing cultural and architectural language that has been replaced with the informal and "random" construction spreading in our nation. The following confirms these findings:

Proposal 1 presents a lightweight structural component. It can be observed that the use of palm fronds in buildings bestows a strong structural component and a cultural essence, involving a long living labor of skill and craftsmanship in Upper Egypt. The material displays strength of fabric in addition to the material's tendency to be shaped and intertwined. The use of the material achieves a strong connection to Upper Egypt's sub-communities and maintains common ground of interest through material exchange in a process of expanding and developing an unappreciated and unused waste material. The proposed wall section will also introduce a strong bond to the lower Egyptian sub-communities and villages, forming another platform based on common interest and exchange of material; developing and spreading a structural component of low cost and a highly environmental performance.

Proposal 2 introduces a building block that uses the Khayala site's waste stone to generate a high performance environmental building component that does not require the use of bonding material, and connects using a method of interlocking. Moreover, the material is of high strength and could be used as a self-sustaining structural element. Introducing this building block will build a connection with suppliers of materials such as cement and sand and will present to the community a building block that could be aesthetically utilized besides its functional and structural capabilities in an attempt to initiate a new movement towards "natural material" facades. The material in comparison with the dominant existing building material of red brick provides higher environmental and physical performance. Regarding the cost of using this block to form walls, the composition has proven to be economical within the price range of both the single brick and double brick. The weakness of the material lies in its bulkiness; $50 \mathrm{~cm}$ length, $20 \mathrm{~cm}$ height and $30 \mathrm{~cm}$ depth, which limits the component's flexibility in building and design.

Proposal 3, offers the stone paste wall configuration, accordingly, it is observed that the developed methodology and mixture component will open doors to unordinary designs, with the ability of the component to form endless configurations due to its fluidity and smoothness prior to hardening. The component could be characterized as tough, and is able to compose solid elements that are classified as aesthetical decorative elements, giving it an advantage over gypsum decorative products due to its toughness and durability. The production of this component will create a connection between the site with the neighboring subcommunity of Ain El Sira that works with gypsum to create decorative cornices and components. The material could be classified as economic and has a high propensity to compete in the local market.

To conclude, Egypt is a land that possesses a wide range of resources that are unused and barely fulfilling their great potentials. It is the role of thinkers and scientists to connect the dots and work on finding adequate approaches of building common grounds of interest and connecting people through the available resources. Egypt today is a divided nation due to reasons that as seen could be categorized as socio-political but in the roots lies an economic query for prosperity and livelihood. In order to rise and unite, one must start with simple solutions, that do not intimidate or discourage the intended beneficiaries with extreme changes and modifications, but rather present them with efficient methods and tools of treatment that allow them to be both the "actors and the viewers" of development. The model envisioned in the Khayala site is merely a starting point; by the development of the available resources and empowerment of people, the Khayala site would hopefully expand and develop its craft, gain profit, make connections and on the long run, re-shape the heritage of tomorrow by altering the dominant form of construction and opening doors to innovation.

Note: Prices used are based on prices in the year 2014.

\section{REFERENCES}

Bowman, M., Ahmad, A.E., Alyhassan, O.S. and Khalil, M.M. (1992). Surveying of some date palm parameters and properties to be utilized in date palm mechanization. Agricultural mechanization in Asia and Africa and Latin America, 23(2), 67-69.

A. Ramezanianpour, F. Gafarpour, M.H. Majedi, Use of rice husk in the production of masonary cements, Building and Housing Research Center (BHRC), September 1997.

Al-Baijat, Hamadallah. "The Use of Basalt Aggregates in Concrete Mixes in Jordan ." Jordan Journal of Civil Engineering. 2.1 (2008): 63-70. Print. <http://elearning. just.edu.jo/jjce/issues/paper.php?p=40.pdf $>$.

Jana, Revedin. Empowerment by Participative Design The Urban Laboratory Zabbaleen. Locus Foundation.org. UNESCO, 2012. Web. 15 Oct. 2013.

"DVV | Adult Illiteracy, Brain Architecture, and Empowerment of the Poor." Dvv International. N.p., n.d. Web. 06 Dec. 2013.

GIZ, and KFW. Participatory Upgrading of Informal Areas: A Decision-makers' Guide for Action. Participatory Development Programme in Urban Areas in Egypt. Cairo: Participatory Development Programme in Urban Areas (PDP) in Egypt, 2012. Print

GIZ. Knowing Local Communities: Guide. Cairo: Participatory Development Programme in Urban Areas (PDP) in Egypt, 2012. Print.

GIZ (2). Maximizing Use Value: Action Guide for Informal Areas. Participatory Development Programme in Urban Areas in Egypt. CAiro: Participatory Development Programme in Urban Areas (PDP) in Egypt, 2012. Print

Kerama Jahromi, M., Jafari A., Rafiee S. and Mohtasebi, S.S. (2007). A survey on some physical properties of the Date Palm tree. Journal of Agricultural Technology, 3(2): 317-322.

Khoddam Razavi, S. R, "Rice husk ash a mineral admixture for high performance concrete", Msc Thesis, Amirkabir University of Technology Press, 2005.

Marthong, C. "Effect of Rice Husk Ash (RHA) as Partial Replacement of Cement on Concrete Properties."International Journal of Engineering Research \& Technology (IJERT). 1.6 (2012): n. page. Web. 18 Dec. 2013.

Mehta, P.K., "High-performance, high-volume fly ash concrete for sustainable development", Proceedings of the 
International Workshop on Sustainable Development and Concrete Technology, Beijing, China, May 20-21, 2004.

M. Zhang, V. M. Malhotra, "High-Performance Concrete Incorporating Rice Husk Ash as a Supplementary Cementing Material", ACI Materials Journal, November-December 1996, Tittle no. 93-M72, PP. 629-636.

MOPIC, "Participatory Development Programme in Urban Areas." Participatory Development Programme in Urban Areas RSS. Egyptian Ministry of Planning and International Cooperation (MOPIC), Spring 2004. Web. 21 Sept. 2013. <http://egypturban.net/about-pdp>.

Ramezanianpour, A.A. "The Effect of Rice Husk Ash on Mechanical Properties and Durability of Sustainable Concretes." International Journal of Civil Engineerng. 7.2 (2009): n. page. Web. 18 Dec. 2013.

Robertson, Eugene. United States. United States Department of The Interior Geological Survey. Thermal Properties of Rocks. 1988. Print. <http://pubs.usgs.gov/of/1988/0441/ report.pdf>.

Shamsi, M. "Some physical and mechanical properties of date palm trees related to cultural operations industry mechanization ." Journal of Agricultural Technology. 5.
(2009): 17-31. Web. 18 Dec. 2013. <http://ijataatsea.com/pdf/June_v5_n1_09/3-10-IJAT2008_37F.pdf>.

Sims, David, and Janet L. Abu-Lughod. Understanding Cairo: The Logic of a City out of Control. Cairo: American University in Cairo, 2010. Print.

Sosna, K. "Laboratory determination of the mechanical properties of granite rocks ." ARCADIS Geotechnika Inc. 988.4 n. page. Web. 18 Dec. 2013. <http://www.kiviniria.nl/ eygec/papers/49 DS Sosna.pdf>.

Subramanian, N. "Sustainability of RCC Structures Using Basalt Composite Rebars S." Masterbuilder. (2010): 156-164. Web. 18 Dec. 2013. <http://www.sefindia.org/?q=system/ files/Sustainability of RCC using Basalt composite RebarsMasterBuilder-Sept2010.pdf>.

Suryawanshi, D.G. India. National Research Laboratory for Conservation of Cutural Property.Basic Studies on the Properties of Palm Leaf. Lucknow: Paper, Web 13 December 2013.

Torabi, Anita. "Insight into petrophysical properties of deformed sandstone reservoirs." AAPG Bulletin. 97.4 (2013): 619-637. Web. 18 Dec. 2013. <http://folk.uib.no/nglhe/ Papers/AAPG 2013 Torabi, Fossen \& Braathen.pdf>. 